\title{
CONSTRUÇÃO DE UM BRAÇO ROBÓTICO CONTROLADO A PARTIR DE UM FPGA
}

Geovane Mimoso Souza ${ }^{1}$, Martha Ximena torres Delgado ${ }^{2}$, Tiago Xavier Cruz ${ }^{1}$

${ }^{1}$ Dicente e ${ }^{2}$ Docente do Curso de Ciência da Computação da Universidade Estadual de Santa Cruz - UESC, Ilhéus, BA. e-mail: mxtd2000@yahoo.com.br

\section{RESUMO}

Este artigo descreve o processo de desenvolvimento de um braço robótico articulado verticalmente com três juntas de rotação, uma garra de dois dedos e com o controle implementado em um FPGA utilizando VHDL. O processo é divido em três partes e aborda os métodos de projeto e execução da parte mecânica, elétrica e de programação do braço.

Palavras-chave: braço robótico, FPGA, VHDL.

\section{CONSTRUCTION OF A ROBOTIC ARM CONTROLLED BY A FPGA}

\section{ABSTRACT}

This article describes the development process of a vertically articulated robotic arm with three rotation joints, a claw with two fingers and the main controller implemented on a FPGA using VHDL. The process can be split into three parts and it addresses the project and execution while explaining the mechanic, electric and programming nature of the methods of the arm.

Keywords: robot arm, FPGA, VHDL. 


\section{INTRODUÇÃO}

$\mathrm{Na}$ sociedade atual, há uma crescente necessidade de se realizar tarefas nas quais 0 grau de periculosidade é elevado ou que necessitem de alta precisão e produtividade em escala. Para realizar tais tarefas, se faz cada vez mais necessária a presença de dispositivos automatizados que apresentem uma boa relação custo/beneficio, além de um alto grau de confiabilidade e adaptabilidade. A robótica é a área que se preocupa com o desenvolvimento de tais dispositivos, valendo-se de sua característica multidisciplinar busca o desenvolvimento e a integração de técnicas e algoritmos para a criação de robôs cada vez mais evoluídos.

$O$ projeto descrito ao longo deste artigo teve como foco de pesquisa e instrumento de aprendizado, a robótica. Nele, foi projetado e implementado um braço robótico articulado verticalmente com três juntas de rotação, uma garra de dois dedos e controlado por um FPGA utilizando a linguagem de descrição de hardware VHDL, o qual consegue movimentar objetos de acordo com os comandos passados em uma interface de botões.

Este artigo por sua vez, descreve todas as etapas do desenvolvimento do braço citado, detalhando os passos do projeto $\mathrm{e}$ da implementação da parte mecânica, elétrica e de programação. Dessa forma pretende ser uma contribuição pedagógica para ser utilizada em laboratórios permitindo uma possível reprodução. Os demais tópicos deste artigo serão abordados na seguinte ordem: Trabalhos correlatos, metodologia, desenvolvimento do braço, resultados, conclusões e trabalhos futuros.

\section{TRABALHOS CORRELATOS}

Existem muitos trabalhos cujo foco é a área de manipulação com braços mecânicos ou robóticos, porém poucos deles descrevem em detalhes os passos para o seu desenvolvimento impossibilitando assim uma possível reprodução feita por estudantes que desejam aprender na pratica. Em Farias et al. (2010), é descrito o processo de desenvolvimento de um braço mecânico com cinco graus de liberdade, feito em aço utilizando equipamentos especializados para modelar e produzir seus componentes, seu controle é implementado no microcontrolador Atmel AT89S8253. Já em Dias et al. (2011) os autores visam descrever 0 processo de construção de um braço mecânico de baixo custo, com a proposta inicial de ser controlado a partir de um computador programado com a linguagem $\mathrm{C}++_{+}$, porém depois de alguns problemas com interferência, o autor propõe a utilização de um controle implementado em um FPGA através da linguagem VHDL, relatando ainda como seria o seu processo de implementação. Por fim, Lafferty (2005) descreve detalhadamente aspectos do desenvolvimento de um braço robótico com três graus de liberdade e uma garra. Exemplificando as especificações de cada componente da estrutura bem como seu embasamento teórico, seu controle é realizado a partir de um computador que envia os comandos para o sistema de controle do braço que o movimenta.

Fazendo uma analise critica percebe-se que Farias et al. (2010) e Lafferty (2005) apresentam soluções eficientes para seus respectivos objetivos, mas seus projetos utilizam materiais de difícil maleabilidade que necessitariam de um laboratório com equipamentos especializados para a confecção das suas peças o que dificultaria sua reprodução por grupos de alunos em disciplinas da graduação. Contudo, o segundo trabalho apresenta um referencial teórico bastante detalhado e pode ser uma boa referência para a fase de planejamento de um possível projeto. Dias et al. (2011) por sua vez, apresenta projeto 
mais próximo do aqui descrito, pois tenta implementar um braço com materiais de baixo custo e propõe a utilização de um FPGA para controlar o braço, porém o artigo não detalha o processo de desenvolvimento mecânico do braço, além disso $\circ$ projeto não foi efetivamente implementado de maneira funcional.

\section{METODOLOGIA}

Para desenvolver o projeto utilizou-se o ambiente de desenvolvimento ISE 12.1 da Xilinx, a placa de desenvolvimento Basys da Digilent ${ }^{\circledR}$ (baseada no FPGA Spartan-3E da Xilinx), um multímetro digital e uma fonte regulável. Por ser um projeto artesanal e caseiro, foram utilizados ainda alguns materiais como serra, ferro de passar, pistola de cola quente, lixa entre outros citados com mais detalhes no tópico desenvolvimento.

Os equipamentos que compõem a estrutura do braço foram adquiridos em sites de compra e venda, em lojas de eletrônica da cidade ou retirados de materiais descartados.

O processo de desenvolvimento propriamente dito prosseguiu seguindo o seguinte ciclo: problema, pesquisa, escolhas e implementação. Primeiramente foi desenvolvida a parte mecânica, depois a elétrica e por fim a de programação, cada uma com seus próprios ciclos de desenvolvimento.

Um exemplo prático desse processo pode ser visto abaixo e se refere a um dos ciclos de desenvolvimento da parte mecânica do braço.

- Problema: definir o material da estrutura do braço, considerando seu pequeno porte, custo final, acabamento final e a dificuldade para modelar com materiais caseiros.

- Pesquisa bibliográfica: estudo dos tipos de materiais mais utilizados para braços robóticos e sua adequabilidade aos requisitos do problema, a partir desse estudo foram selecionados os seguintes materiais: poliestireno, acrílico, madeira e aço;

- Utilizando os dados extraídos da pesquisa bibliográfica é possível comparar os prós e contras de cada material:

- Poliestireno: Leve, resistência mediana, barato, moldável, acabamento ruim.

- Madeira: Pesada, resistente, barata, moldável, acabamento razoável.

- Acrílico: leve, resistência mediana, preço mediano, moldável, ótimo acabamento.

- Aço: Pesado, muito resistente, caro, difícil moldagem, bom acabamento.

Com os dados e sabendo que para parte superior do braço, a leveza é fundamental, sobram apenas o acrílico e poliestireno. Já para a parte inferior a resistência é o mais importante e o peso não é tão relevante, sendo assim restam a madeira e o aço. Comparando os outros dados podemos ver que tanto o acrílico quanto o poliestireno são moldáveis e possuem resistência mediana, porém diferem no preço e no acabamento. Considerando que a diferença de preço não é muito grande e que o acabamento do acrílico é bem melhor, optou-se pelo acrílico para a parte superior, já para a inferior a difícil modelagem e 0 alto preço do aço foram determinantes para a escolha da madeira.

- Os cortes das peças foram realizados para cada parte de acordo com as especificações definidas no ciclo referente á definição da estrutura do braço.

\section{DESENVOLVIMENTO DO BRAÇO}

\subsection{Parte mecânica}

O modelo de braço robótico com articulação vertical e três juntas de revolução foi o escolhido para este projeto, tal modelo utiliza juntas de rotação e possui uma área de atuação maior em relação aos outros modelos existentes 
com o mesmo número de articulações. (FRANCHIN, 1999).

Para uma melhor organização e entendimento da estrutura do braço (Figura 1), podemos dividi-la em cinco partes principais: base $(A)$, vínculo $1(A-B)$, vínculo $2(B-C)$, vinculo 3 (C-D) e garra (D-E).

Ainda na Figura 1, estão detalhadas algumas medidas, são elas:

LAB: medida correspondente a altura do atuador que interliga o vínculo 1 ao 2 em relação ao apoio da estrutura do braço.
LBC: medida correspondente a parte do comprimento do vínculo 2 que fica situada entre os atuadores da sua parte superior e inferior.

LCD: medida correspondente ao comprimento do vínculo 3 que vai do atuador que interliga 0 vinculo 2 ao 3 até o inicio da sua junção com a garra do braço.

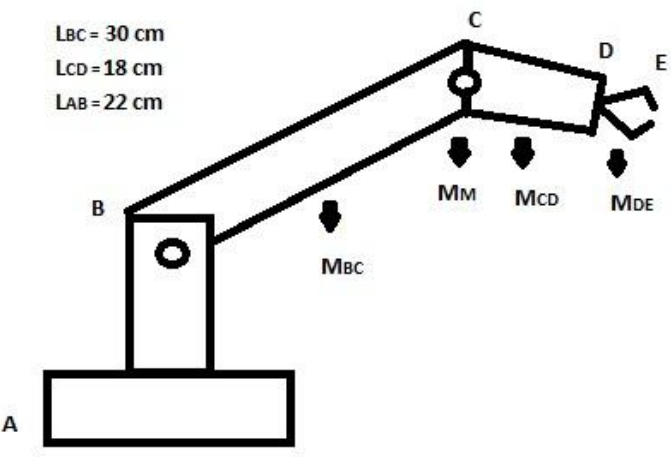

Figura 1. Estrutura do Braço, com suas medidas e forças representativas.

Todas essas medidas são definidas de acordo com a necessidade de alcance do braço, e são determinantes para o cálculo de torque que cada atuador deve ter. Por tanto ao defini-las deve-se considerar os requisitos da estrutura $e$ considerar as equações de (1) a (3).

Considerando os dados relativos às medidas úteis dos vínculos e já tendo definido o tipo de braço a ser construído, podemos calcular o volume da região de trabalho do braço, expresso pela equação (1).

$$
\text { (1) } \quad \begin{aligned}
V & =33,51{ }^{*} \mathrm{LAB} *{ }^{*} \mathrm{LBC}{ }^{*} \mathrm{LCD} \\
\mathrm{V} & =33,51^{*} 0,22^{*} 0,3^{*} 0,18 \\
\mathrm{~V} & \cong \mathbf{0 , 4} \mathbf{m}^{\mathbf{3}}
\end{aligned}
$$

Logo, sabendo-se que a área de trabalho de um braço de articulação vertical é uma esfera (Figura 2), teremos um espaço de trabalho esférico com volume aproximado de $0,4 \mathrm{~m}^{3}$. (FRANCHIN, 1999).

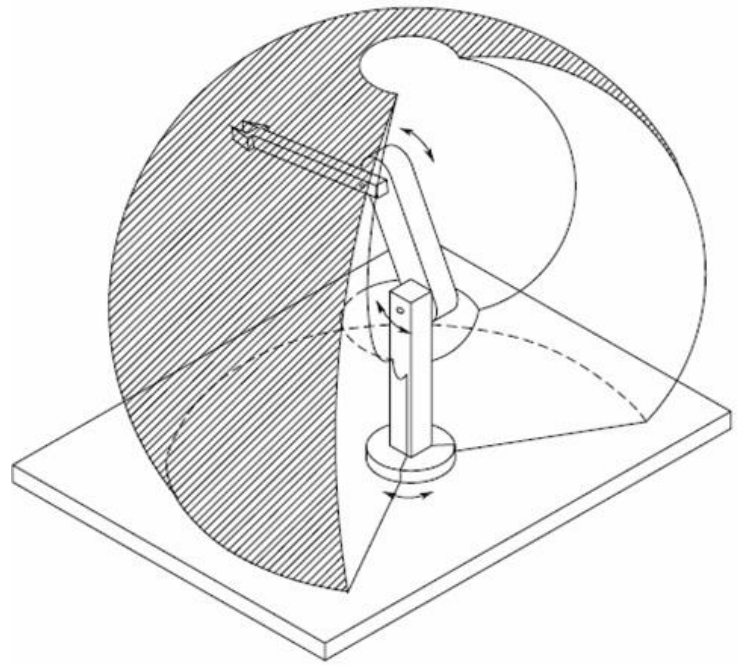

Figura 2. Área de trabalho do braço.

$$
\text { Para definir o torque dos motores }
$$
situados nas duas articulações verticais é necessário primeiro identificar as massas expressas na Figura 1. 
MDE é composta pela massa da garra $80 \mathrm{~g}$, massa do motor da garra $9 \mathrm{~g}$ e a carga útil do braço 100g. Totalizando assim 189g.

MCD e MBC são calculadas levando-se em consideração a densidade do acrílico $\left(1.19 \mathrm{~g} / \mathrm{cm}^{3}\right)$ e volume das partes que as compõem. Além disso, em cada uma delas devem ser adicionadas $15 \mathrm{~g}$ relativas a parafusos e porcas. Totalizando assim respectivamente $151,55 \mathrm{~g}$ e $214,9 \mathrm{~g}$.

MM é massa do atuador que interliga os vínculos 2 e 3 o qual tem massa igual a $39 \mathrm{~g}$.

Com os dados de massa e comprimento apresentados anteriormente e resumidos na Tabela 1, podemos calcular os torques necessários para os atuadores de B (TB) e C (TC), como visto nas equações (2) e (3).

Tabela 1. Dados relativos ao cálculo de torque

\begin{tabular}{lr}
\hline Dados & Valor \\
\hline LBC & $30 \mathrm{~cm}$ \\
LCD & $18 \mathrm{~cm}$ \\
MDE & $0,189 \mathrm{~kg}$ \\
MCD & $0,151 \mathrm{~kg}$ \\
MBC & $0,214 \mathrm{~kg}$ \\
MM & $0,039 \mathrm{~kg}$ \\
\hline
\end{tabular}

(2) $\mathrm{TB}-\mathrm{MDE}^{*}(\mathrm{LBC}+\mathrm{LCD})-\mathrm{MCD}^{*}(\mathrm{LBC}+$ $\mathrm{LCD} / 2)-\mathrm{MM}^{*} \mathrm{LBC}-\mathrm{MBC}^{*} \mathrm{LBC} / 2=0$

$\mathrm{TB}=9,072+5,889+1,17+3,21$

TB $=19,341 \mathrm{Kg} \cdot \mathrm{cm}$

(3) $\mathrm{TC}-\mathrm{MDE}{ }^{*} \mathrm{LCD}-\mathrm{MCD}{ }^{*} \mathrm{LCD} / 2=0$

$\mathrm{TC}=3,402+1,359$

$\mathrm{TC}=4,761 \mathrm{Kg} . \mathrm{cm}$

Tendo a estrutura básica definida e os cálculos estruturais efetuados, pode-se iniciar a descrição do processo de montagem da estrutura do braço. O material predominantemente utilizado foi acrílico, pois além de ser leve e resistente ainda oferece um ótimo acabamento e pode ser encontrado facilmente em lojas de caseMod ou na internet, para este projeto foram adquiridas duas placas de $40 \mathrm{~cm}$ de largura $50 \mathrm{~cm}$ de altura e $4 \mathrm{~mm}$ de espessura. Apenas para a estrutura da base e do vínculo 1, nos quais o peso não é tão relevante e a resistência é mais importante, foi utilizada madeira retirada de um lastro de cama antigo.

Com o intuito de evitar repetições ao longo do texto é necessário ressaltar que todos os cortes, tanto na madeira quanto no acrílico, foram realizados utilizando uma serra elétrica circular e os furos foram feitos utilizado uma furadeira.

A base (Figura 3) foi construída principalmente com madeira reutilizada e foi idealizada para ter uma grande área de apoio relativa ao volume de atuação do braço, proporcionando assim equilíbrio e rigidez a estrutura. Basicamente, foi construído um retângulo vazado de $40 \mathrm{~cm}$ de comprimento e 20 $\mathrm{cm}$ de largura, porém os dois lados menores do retângulo foram deslocados para a parte mais central com o intuito de formar um quadrado de $20 \mathrm{~cm}$ de lado, para facilitar o acoplamento das outras partes e proporcionar mais rigidez a base. Para, a montagem da estrutura foram cortados quatro pedaços de madeira: dois com $20 \mathrm{~cm} x$ $3 \mathrm{~cm} \times 4 \mathrm{~cm}$ e dois com $40 \mathrm{~cm} \times 3 \mathrm{~cm} \times 4 \mathrm{~cm}$ de comprimento, largura e altura respectivamente, que foram presos utilizando pregos. Logo acima da parte quadrada central, foram pregados dois outros pedaços de madeira mais finos e largos com $20 \mathrm{~cm} \times 4 \mathrm{~cm} \times 0.7 \mathrm{~cm}$, de maneira que fosse possível parafusar um quadrado, feito de acrílico, de $20 \mathrm{~cm}$ de lado a estrutura. No centro desse quadrado há ainda cinco furos para possibilitar o acoplamento do atuador da base. 


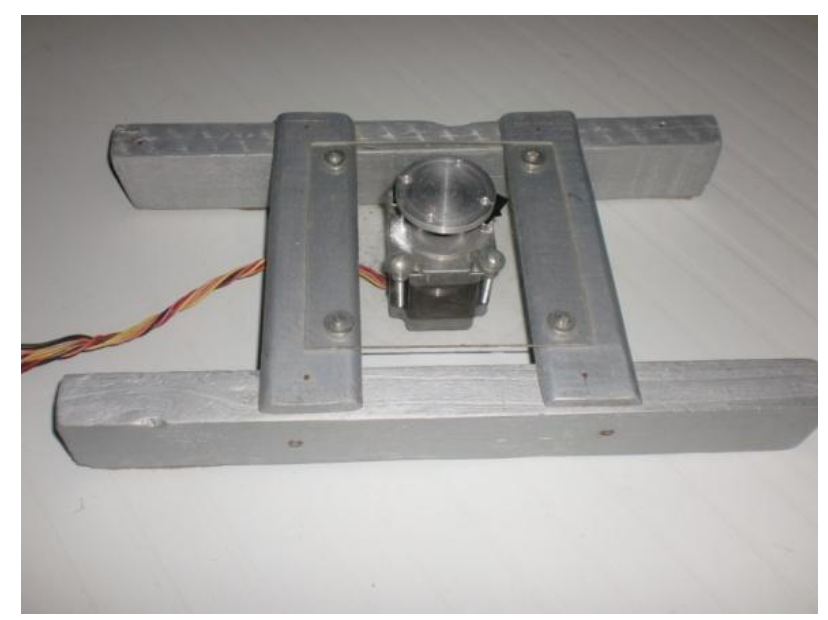

Figura 3. Base.

O vínculo 1 (Figura 4) foi feito com madeira e tem a função de haste central e deve suportar toda a movimentação vertical de braço, portanto deve ser firme e pequena para não limitar os movimentos dos vínculos superiores. Para sua montagem foram cortados três pedaços de madeira dois com $12 \mathrm{~cm} \times 4 \mathrm{~cm} \times 0.7 \mathrm{~cm}$ e um com $10 \mathrm{~cm} \times 4 \mathrm{~cm} \times 0.7 \mathrm{~cm}$, que depois foram presos com pregos para formar uma estrutura retangular sem um dos lados. Nas duas pontas superiores dessa estrutura foram feitos cinco furos em cada para o posterior acoplamento de dois horns de servos (Figura 5), que são peças que se encaixam nos servos e facilitam o acoplamento deles a outras peças. Além disso, no centro da peça que serve de base foram feitos quatro furos, para possibilitar o encaixe com o elo de alumínio (Figura 6) que liga o atuador da base ao vinculo 1. Para produção desse elo, foi necessário projetá-lo e passar suas especificações para um torneiro mecânico que o confeccionou em alumínio.

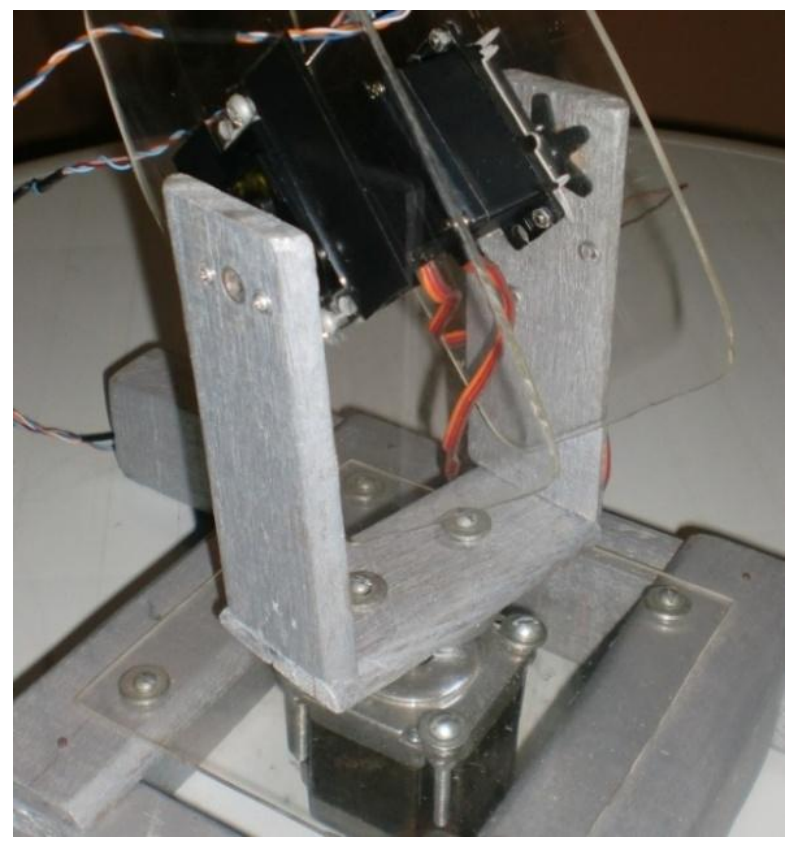

Figura 4. Vinculo 1. 


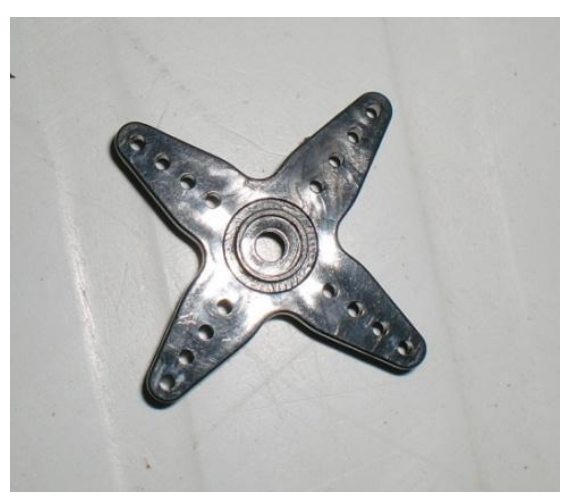

Figura 5. Horn do servo.

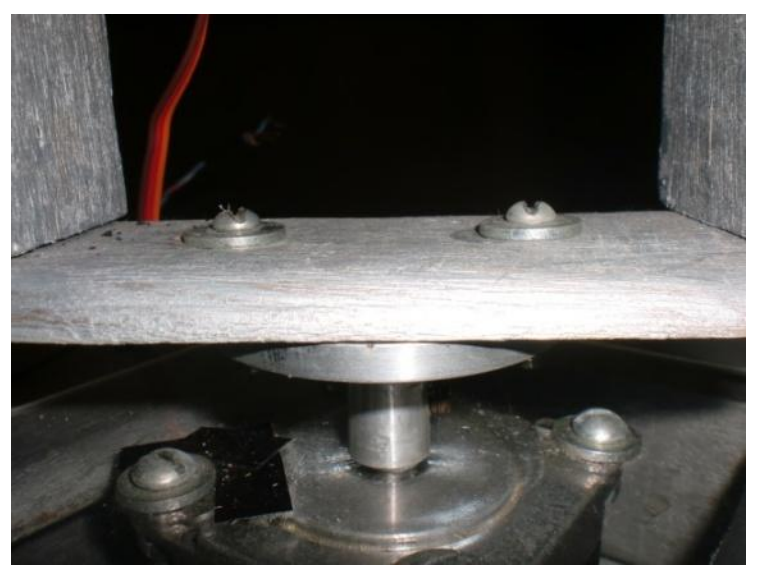

Figura 6. Elo de alumínio.

O Vínculo 2 (Figura 7) foi construído todo em acrílico e têm medidas variáveis ao longo da sua estrutura, isso foi feito para que o peso nas partes mais distantes da base fosse menor, além disso, este vínculo tem duas angulações ao longo de sua estrutura. A primeira de cerca de 20 graus localizada logo após o encaixe com a base e a segunda com cerca de 70 graus inserida um pouco antes do encaixe com o vínculo 3 , tais angulações tem por finalidade possibilitar uma movimentação pendular e mais abrangente do vínculo 3 em relação a sua área de atuação, seu comprimento total é de $40 \mathrm{~cm}$. Para sua confecção foram cortados dois pedaços iguais a partir da placa de acrílico de $40 \mathrm{~cm} \times 50 \mathrm{~cm} \times 4$ $\mathrm{mm}$ citada anteriormente. Em cada um desses pedaços foi feito um furo no centro para interligar os pedaços através de um parafuso e quatro porcas e quatro furos e uma fissura entre eles, na parte inferior, para conectar um servo motor. Outro ponto importante é que em apenas uma das partes foram feitos cinco furos na ponta superior para o encaixe de um horn de servo motor e na outra parte apenas um furo. Os furos com o horn e o furo na parte superior servirão posteriormente para encaixar o vínculo 2 ao 3, já o parafuso inserido no centro do vinculo 2 visa garantir uma maior rigidez para a estrutura possibilitando assim movimentos mais precisos e por fim o encaixe para o servo na parte inferior irá conectar o vinculo 1 ao 2, ao passo que conecta o horn do vinculo 1 ao servo motor do vinculo 2 . 


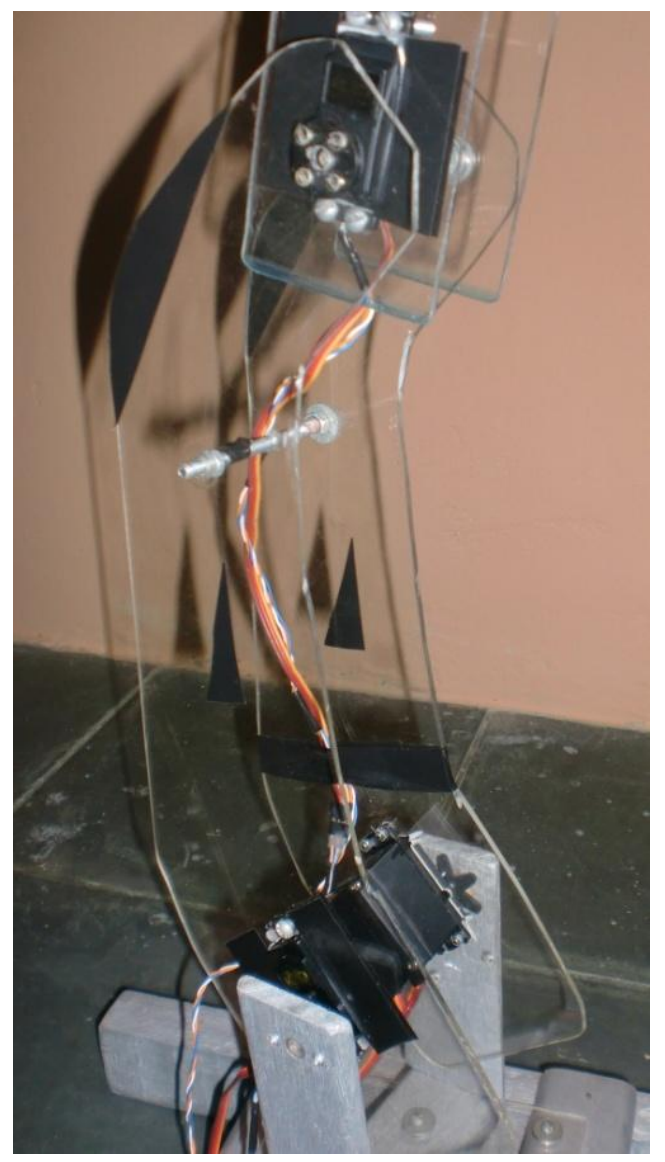

Figura 7. Vínculo 2.

O Vínculo 3 (Figura 8) é feito a partir de dois pedaços retangulares de acrílico de $21 \mathrm{~cm} \mathrm{x}$ $6 \mathrm{~cm} \times 4 \mathrm{~mm}$, tais pedaços são interligados com um parafuso e quatro porcas que atravessam o centro da estrutura e assim como o colocado no vínculo 2 tem o objetivo de oferecer maior rigidez e precisão. Na parte que se conecta ao vinculo 2 , em um dos retângulos são feitos quatro furos e uma fissura para o encaixe de um servo motor, no outro retângulo é feito apenas um furo, para a colocação de um parafuso com porca auto travante. O servo motor se conecta ao horn inserido na parte superior do vínculo 2 e o parafuso com porta auto travante encaixa o furo do vinculo 2 com o do 3 , este tipo de parafuso foi necessário pois ela fica em um junta e um parafuso comum folgaria com a movimentação da junta, além disso a colocação de outro motor, como na junta entre o vinculo 1 e 2 , não era necessária pois a necessidade de torque dessa junta é menor. Por fim, para parte superior onde a garra é encaixada, foi cortado um retângulo de acrílico com $5 \mathrm{~cm} \times 7 \mathrm{~cm}$, o qual foi colado com cola quente na ponta do vinculo 3 . Ainda neste retângulo são feitos quatro furos para que assim a garra possa ser parafusada nele. 


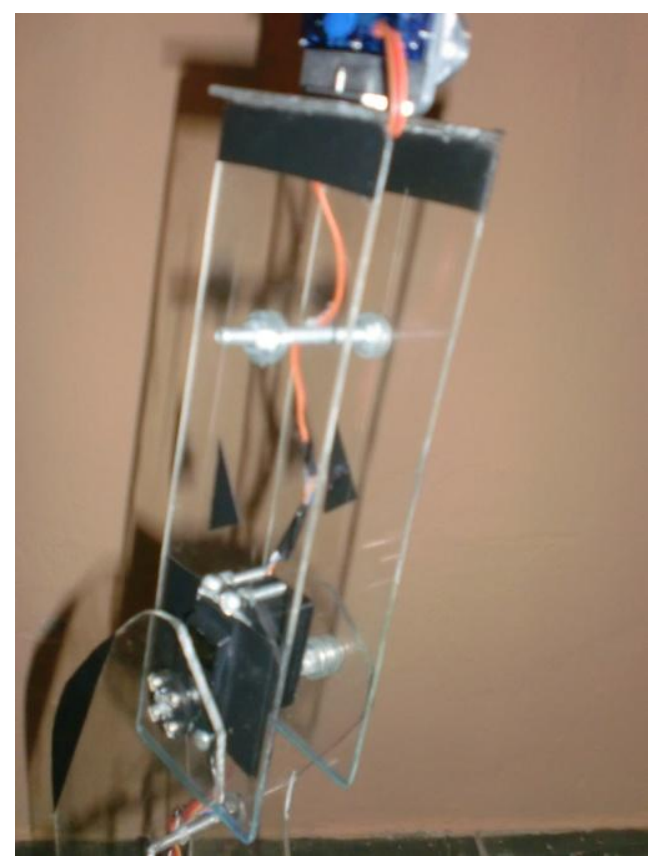

Figura 8. Vinculo 3.

A garra escolhida foi uma garra de dois dedos feita em alumínio que possui $9,2 \mathrm{~cm}$ de comprimento e $4,6 \mathrm{~cm}$ de largura com a garra fechada, $6,5 \mathrm{~cm}$ de comprimento e $8,9 \mathrm{~cm}$ de largura com a garra aberta, além de possuir uma abertura máxima de $5,7 \mathrm{~cm}$ (Figura 9). Para seu controle ela possui o encaixe necessário para ser controlada a partir de um micro servo. Esta garra foi feita em uma oficina especializada e adquirida para o projeto. Suas principais características são leveza $80 \mathrm{~g}$ e precisão.

Por fim, depois de feitas todas as junções necessárias obtêm-se a estrutura final que pode ser vista na Figura 10.

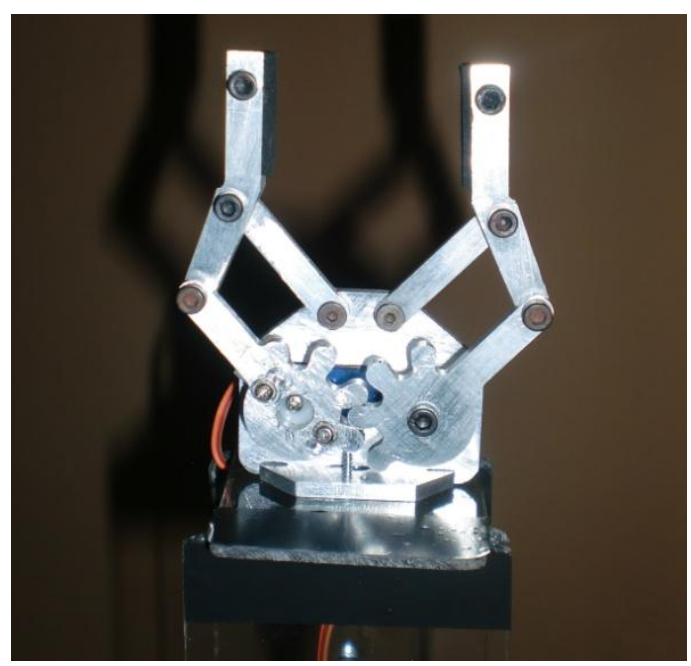

Figura 9. Garra. 


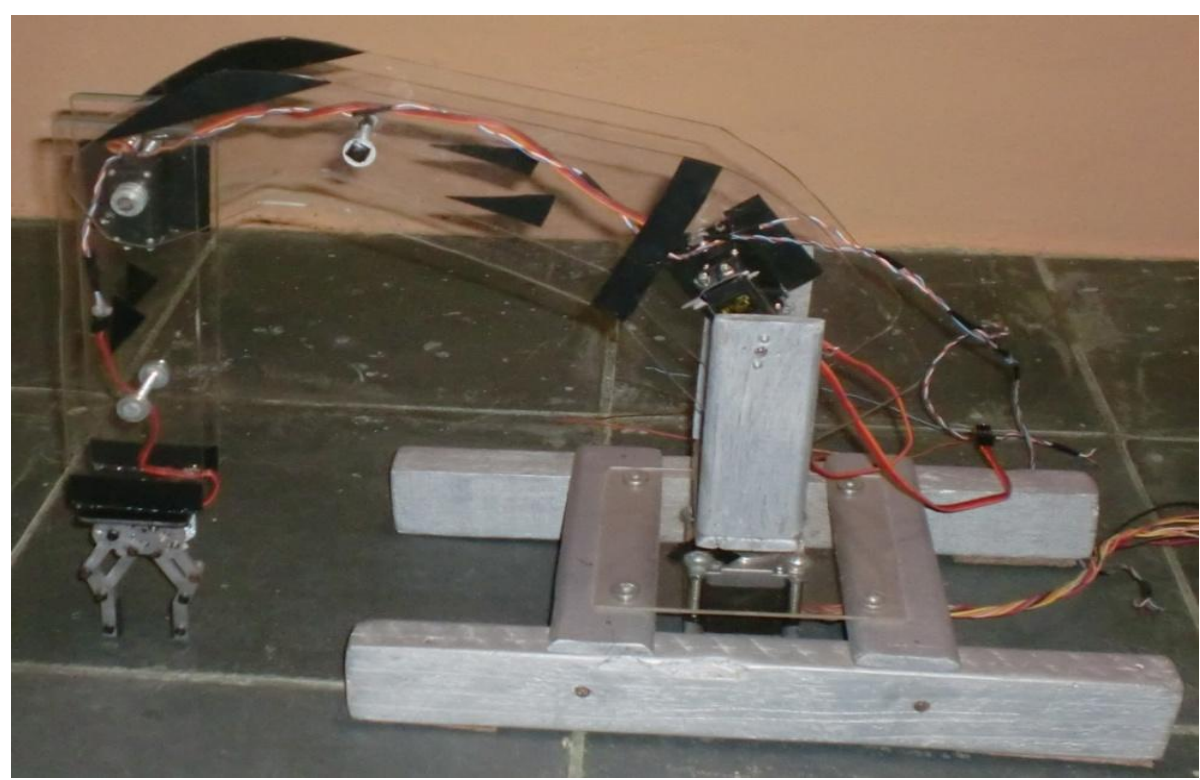

Figura 10. Estrutura fina.

\section{PARTE ELÉTRICA}

Para movimentar a estrutura apresentada anteriormente são utilizados cinco motores, sendo quatro servos-motores e um motor de passo bipolar. O motor de passo bipolar foi utilizado na base devido ao seu controle por passos, o que permite uma movimentação cadenciada e precisa, além de um torque mais forte em relação aos motores de passo unipolares. O modelo utilizado foi o SM 1.8-D12-MN da Action Technology.

Já para as demais articulações do braço foram utilizados servo motores, por apresentarem um torque continuo e uma menor predisposição a erro em situações de resistência ao seu movimento. Além disso, sua relação torque/peso é consideravelmente maior que a dos motores de passo, características desejáveis tanto para as articulações verticais quanto para a garra.

Os resultados dos cálculos de torque encontrados nas equações (2) e (3), bem como características como preço, disponibilidade e peso foram utilizadas para definir quais servomotores seriam adquiridos para o projeto. Após as a devidas avaliações foram feitas as seguintes escolhas: Para a articulação diretamente vinculada a base (Figura 4) são utilizados dois servos TowerPro MG995 que pesam cada um $55 \mathrm{~g}$ e tem um torque de $12 \mathrm{~kg} . \mathrm{cm}$. Já para a segunda articulação (Figura 7) o servo motor escolhido foi o Hextronic 5010 que tem $6,5 \mathrm{~kg} . \mathrm{cm}$ de torque e pesa $39 \mathrm{~g}$. Por fim, para garra foi preciso um servo leve e com torque superior a 1,5 kg.cm, logo o servo Tower pro 590 com 1,8 kg.cm e pesando $9 \mathrm{~g}$ foi o escolhido.

Para controle dos atuadores utilizou-se a placa Digilent Basys que possui na sua estrutura dezesseis sinais de controle (CMOS), dos quais cinco foram utilizados para enviar sinais para os atuadores. Desses sinais três são conectados diretamente nos servos-motores, isso pode ser feito, pois eles são controlados através de sinais PWM (BARR, 2001) que são enviados por um circuito modulador PWM implementado na própria Basys. Além disso, os dois servos da articulação um são controlados pelo mesmo sinal, isso é possível, pois ales são inseridos de maneira simétrica um oposto ao outro e movimentam o braço no mesmo sentido quando recebem 0 mesmo sinal.

Quanto aos motores de passo bipolares, como eles têm enrolamentos separados, uma 
conexão direta não pode ser feita, pois se faz necessária uma polarização reversa durante a operação de controle para o passo acontecer. Essa polarização deve ser gerada através de um circuito ponte $\mathrm{H}$, inexistente na placa Basys. Portanto, foi necessário desenvolver um circuito externo que receba os sinais de controle da Basys e gere a sequência ponte $H$ necessária para a movimentação correta do motor.

O circuito mencionado anteriormente foi desenvolvido para receber dois sinais de controle em nível CMOS e gerar a sequência ponte $H$ correspondente ao passo especificado pelos sinais. Como base para sua criação utilizou-se o circuito integrado LN298 que, de maneira geral, recebe quatro sinais lógicos e de acordo com as entradas pode alterar o fluxo de corrente das suas duas ponte H's. O Cl LN298 possui ainda uma alimentação lógica que pode variar entre $3.3 v$ e $5 v$ e outra referente a tensão de saída para os motores, que pode ser alimentada de acordo com sua necessidade, no caso deste projeto, $5 \mathrm{v}$.

Com o intuito de obter um melhor aproveitamento das saídas de controle da Basys, o circuito externo foi projetado para aproveitar o padrão repetitivo da tabela de controle do motor de passo bipolar (Tabela 2). Nela, os valores das entradas dois e quatro são correspondentes a inversão das entradas um e três respectivamente, permitindo assim a utilização de transistores para realizar essa inversão. Por fim, são utilizados oito diodos para proteger as saídas do circuito e um capacitor para manter a alimentação contínua.

Para a confecção da placa de interface em questão, foi necessário primeiramente criar o projeto do circuito especificando todos os componentes e suas ligações no software EAGLE versão 5.11 (Figura 11). A partir dessa especificação o EAGLE organiza as rotas por onde irão passar as conexões do circuito e por fim gera um arquivo no formato PDF contendo todas as trilhas do circuito impresso organizadas (Figura 12).

Tabela 2. Sequência de passos para movimentação.

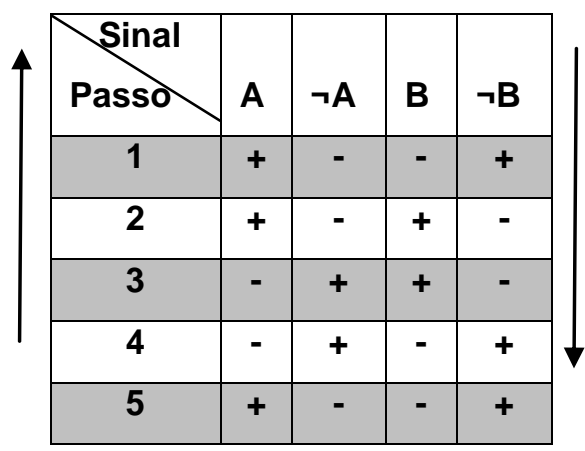

A partir do arquivo PDF contendo todas as trilhas, utilizou-se o processo descrito por Carneiro (2005) para confeccionar a placa vista na Figura 13. 


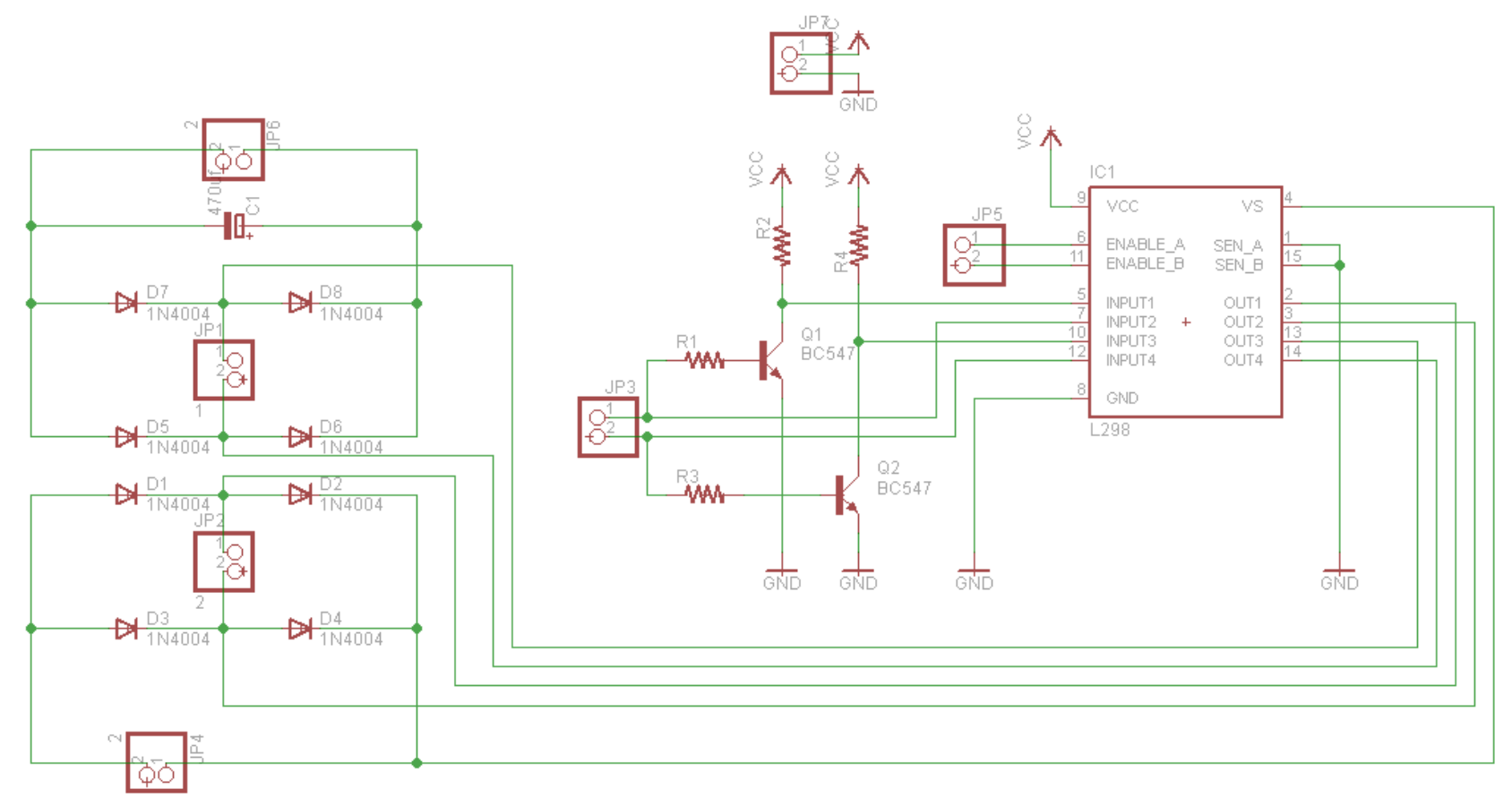

Figura 11. Circuito externo responsável controle do motor de passo bipolar.

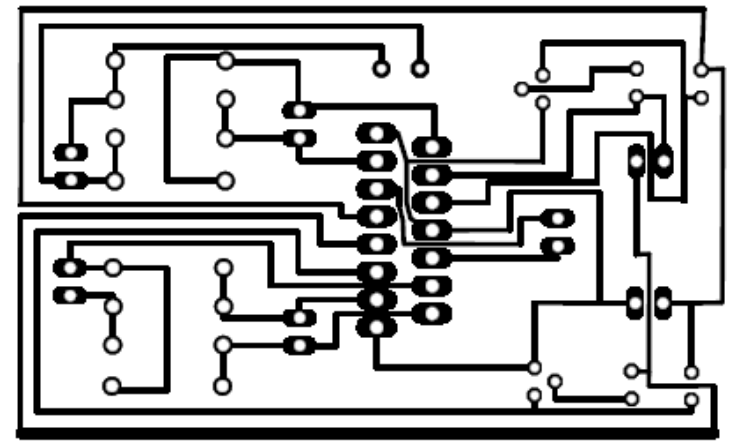

Figura 12. Trilhas do circuito impresso.

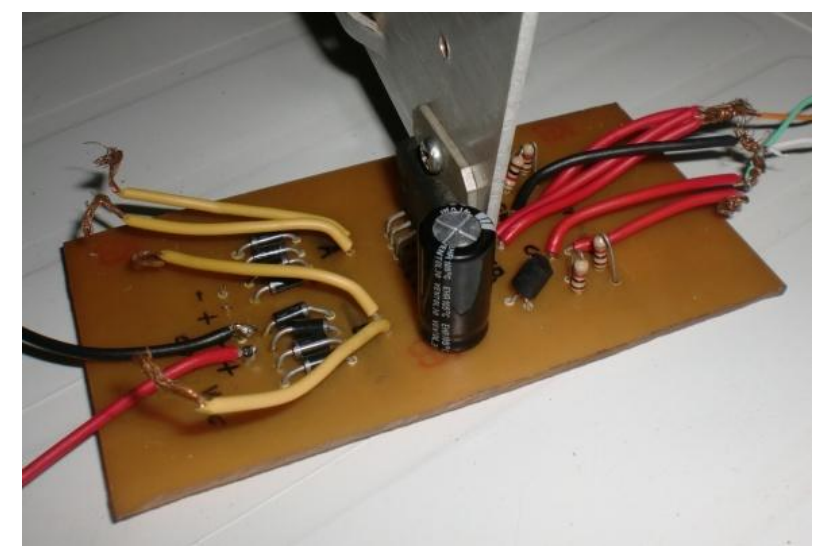

Figura 13. Circuito completo. 
Outra adaptação necessária diz respeito ao número de entradas do motor de passo bipolar SM 1.8-D12-MN. Como este motor tem oito entradas e o circuito gerado para seu controle, por questões de custo e eficiência, conta com apenas quatro saídas, foi necessário ligar as entradas do motor de forma que duas bobinas fossem controladas como apenas uma (Figura 14). Dessa forma, levando-se em consideração que o motor em questão possui quatro bobinas e cada bobina necessita de duas entradas, obtemos então o número desejado de apenas quatro entradas.

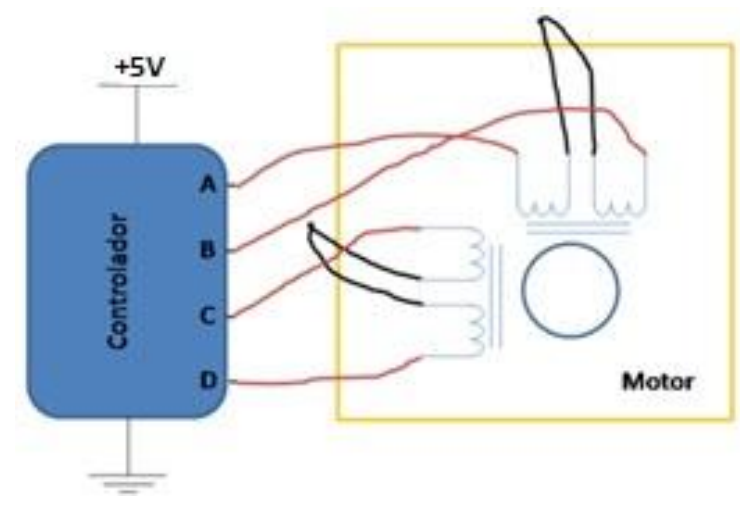

Figura 14. Forma de ligação para um motor bipolar com oito fios.

Por fim, para interligar o controle do braço aos seus atuadores foram utilizados os fios internos aos cabos de par trançado, por serem: finos, resistentes e encontrados com facilidade devido a sua larga utilização em conexões de internet.

\section{Parte de programação}

O controle de toda essa estrutura é implementado utilizando a linguagem de descrição de hardware VHDL, sendo o código de controle compilado e inserido no FPGA da placa Basys da Digilent. Tal código utiliza um recurso da linguagem VHDL chamado de instanciação de componentes (D'AMORE, 2005). Este recurso permite que um componente descrito em outro código possa ser instanciado e utilizado varias vezes com diferentes parâmetros dentro do código principal. Valendo-se desse principio, criou-se então um controlador para servosmotores e outro para motores de passo bipolar.
A partir desses controles, no código principal foram instanciados três servos motores e um motor de passo bipolar, cada um com seus respectivos parâmetros e suas entradas e saídas correspondentes. No total o código principal possui oito entradas e cinco saídas, sendo duas entradas e duas saídas para o motor de passo bipolar e duas entradas e uma saída para cada servo-motor.

Como cada motor possui duas entradas, é possível girar os motores em sentidos diferentes e mantê-lo parado caso ambas as entradas estejam desligadas permitindo assim o controle total de todas às articulações através da interface de switches da placa Basys. Já as saídas são compostas pelos os três PWM's relativos a cada uma das articulações que utilizam servos, além de duas saídas correspondentes à sequência de bits necessária para a ativação do circuito ponte $\mathrm{H}$ que movimenta o motor base. 
Motor de passo bipolar: $O$ controle do motor de passo funciona em conjunto com 0 circuito externo (Figura 13) para gerar a alternância expressa na Tabela 2. Para cada fluxo de corrente positivo o controle envia ' 1 ' para o circuito externo e para o fluxo de corrente negativo o controle envia ' 0 '.

Exemplificando: Para dar 0 primeiro passo indicado na Tabela 2 a saída correspondente seria o seguinte vetor: $(1,0,0,1)$ que depois de interpretado pelo circuito de controle externo passa para o motor de passo bipolar a seguinte saída: $(+,-,-,++)$. Porém, como as saídas um e três são inversamente correspondentes as saídas dois e quatro, o circuito de controle inserido na Basys precisa apenas enviar o valor de um e três, logo a saída correta seria $(1,0)$. Sendo assim, o circuito de controle pode movimentar o motor de passo bipolar atualizando os dois bits de controle dentro da freqüência suportada pelo motor ou da velocidade desejada.

Para determinar a velocidade em que os passos são efetuados um divisor de freqüência é implementando, já para determinar a direção dos passos um contador de dois bits é incrementado ou decrementado de acordo com a direção desejada. A partir do valor do contador um switch seleciona a sequência de bits a ser enviada para as saídas.

Servo motor: Para controle dos servos é necessário a utilização de circuito modulador PWM, como esse tipo de circuito pode ser inteiramente implementado em um FPGA, não foi necessário a criação de um circuito externo a placa Basys. O controle via PWM é realizado de acordo com o tamanho do pulso passado na entrada em um determinado tempo. No caso dos servos motores esse tempo é de 20 milissegundos, dentro desse tempo dependendo da largura de pulso enviada no inicio do período, de 1 a 2 milissegundos o motor pode variar de $90^{\circ}$ a $90^{\circ}$.

Para gerar esse pulso é necessário determinar primeiro o número de interrupções de clock que são efetuadas dentro do período de 20 ms, no caso desse projeto utilizou-se a freqüência de $50 \mathrm{Mhz}$, desse modo, de acordo com a equação (4), temos 1000000 de interrupções nesse período. Seguindo o mesmo padrão determina-se então o número de interrupções referentes ao valor mínimo e máximo do pulso de posicionamento do servo, sendo assim, para $1 \mathrm{~ms}$ e $2 \mathrm{~ms}$ temos respectivamente 50000 e 100000 interrupções. Com esses valores é possível determinar, utilizando um contador, o inicio de cada novo período e enviar no inicio de cada um deles valores lógicos iguais a ' 1 ' variando dentro dos limites que determinam a posição do servo.

$$
\text { (4) } \begin{aligned}
\mathrm{T} & =1 / \mathrm{F} \\
\mathrm{T} & =1 / 50^{*} 10^{6} \\
\mathrm{~T} & =20 \mathrm{~ns} \\
\mathrm{I} & =\mathbf{2 0} \mathrm{ms} / 20 \mathrm{~ns}=\mathbf{1 0 0 0 0 0 0}
\end{aligned}
$$

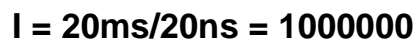

O sentido de rotação é definido decrementado ou incrementando uma variável de controle de posicionamento, já á velocidade de rotação do motor é definida de acordo com o tamanho desse incremento ou decremento.

Outro ponto importante, é que como esse código deve servir para diferentes articulações, foi necessário utilizar a descrição de variáveis genéricas (D'AMORE, 2005) para possibilitar a configuração especifica de cada servo instanciado no código principal. Possibilitando assim, a configuração da posição mínima e máxima de variação de cada um, além da sua velocidade.

\section{RESULTADOS}

Foi construído satisfatoriamente o braço robótico articulado verticalmente com três juntas de rotação, uma garra de dois dedos e com o 
controle implementado em um FPGA utilizando VHDL, conseguindo dessa forma mover objetos ao seu redor de acordo com os comandos passados através da interface de botões da placa Basys.

Mesmo desenvolvendo o projeto de maneira satisfatória é importante ressaltar alguns aspectos que podem ser aperfeiçoados. Um exemplo claro disso são os servos motores utilizados no projeto, esses servos são de origem chinesa e têm uma qualidade muito inferior a servos como os da FUTABA e da HITEC. Porém, eles foram escolhidos devido, principalmente, ao seu baixo custo, mas no desenvolvimento do projeto foram demonstrando sua baixa qualidade, como por exemplo, quebras sem motivo aparente e apresentando imprecisão, o que acarretou em atraso na finalização do projeto.

Outro ponto de melhoria seria na espessura do acrílico utilizado, nesse projeto foi utilizando um acrílico com $4 \mathrm{~mm}$ de espessura, porém no momento do seu corte ele apresentava muita fragilidade o que dificultava a confecção das partes necessárias, além disso, com uma espessura maior o resultado final será uma estrutura mais rígida. Uma espessura de $6 \mathrm{~mm}$ á $8 \mathrm{~mm}$ seria ideal, mas novamente o preço foi decisivo e norteou a escolha pelo acrílico de menor espessura.

Por fim, um demonstrativo funcional do braço pode ser visto no seguinte vídeo: www.youtube.com/watch?v=jKxokLsMNOM\&featu re=plcp, no qual pode ser verificado 0 funcionamento dos servos motores e do motor de passo em suas respectivas articulações, bem como a capacidade do braço de mover objetos e colocá-los em locais específicos.

\section{CONCLUSÕES}

Ao fim do trabalho, o braço desenvolvido ao longo do projeto servirá como plataforma para desenvolvimento de aplicações com manipuladores robóticos, oque permitirá que trabalhos em áreas como a de visão computacional e de controle de manipuladores à distância sejam desenvolvidos. Outro fator a ser destacado é que processo de desenvolvimento do projeto descrito nesse artigo possibilitará que professores utilizem-no como trabalho prático para motivar seus alunos a trabalhar com a multidisciplinaridade inerente a robótica.

\section{TRABALHOS FUTUROS}

Já esta sendo desenvolvido um sistema de visão computacional utilizando a biblioteca openCV (ITSEEZ, 2012) que permitirá que o braço aqui descrito possa selecionar objetos de uma cor especifica situados em um ambiente controlado.

É importante ressaltar que utilização de um FPGA para o controle do braço irá facilitar o processo de adição do sistema de visão computacional, visto que as adaptações serão feitas direto no código VHDL que descreve o controle do braço.

\section{REFERÊNCIAS}

BARR, M. Introduction to Pulse Width Modulation. 2001. Disponível em: <http://www.embedded.com/story/OEG20010821 S0096> Acesso em: 14 ago. 2012.

CARNEIRO, U. C. Placa de circuito impresso: método térmico. 2005. Disponível em: <http://www.ulissescarneiro.com/pci.htm> Acesso em: 14 ago. 2012.

D'AMORE, R. VHDL - Descrição e síntese de circuitos digitais. Rio de Janeiro: LTC, 2005.

DIAS, M. et al. Construção de um braço mecânico didático de baixo custo. In: Congresso de Iniciação Científica e III Mostra Científica da UFPEL, 20. Anais... Pelotas, 2011.

FARIAS, B. et al. Braço mecânico para manipulação de $\mathrm{PCl}$ voltado à aplicações de baixo custo. 2010. Disponível em: <http://mecatronica.florianopolis.ifsc.edu.br/pgm/i mages/stories/PIS/2010_1/Artigo.pdf> Acesso em: 14 ago. 2012. 
FRANCHIN, M. N. O braço mecânico. 1999.

Disponível

em:

<http://www.dee.feb.unesp.br/ marcelo/robotica/R obot3.htm>. Acesso em: 14 ago 2012.

ITSEEZ. About OpencV (Open Source Computer Vision Library). 2012. Disponível em: <http://opencv.org/about.html> Acesso em: 14 ago. 2012.

LAFFERTY, A. A robust inexpensive multipurpose robotic arm. Massachusetts: A.I.Technical Report MIT, 2005.

SMITH, D. J. HDL chip design: a practical guide for designing, synthesizing and simulating ASICs and FPGAs using VHDL or Verilog. EUA: Doone Publication, 1998. 